\title{
Prospective Single-Arm Study of Radioprotection by Amifostine in High Dose Radioactive lodine Therapy for Thyroid Cancer
}

Ajay Sandhu, Vladimir loffe, Daniel Karakla, J Trad Wadsworth, April Mendoza, Nikhil Rao

Kathleen Dignan, Elizabeth Mason, Thomas E Goffman

\begin{abstract}
Purpose: Xerostomia, sialoadenitis, taste dysfunction and nausea are well known toxicities following high dose radioactive iodine (RAI) treatment for well-differentiated thyroid cancer. This prospective study sought to determine the incidence rates for RAI adverse effects and to determine, whether the radioprotector, amifostine could decrease the duration of the adverse effects in single treatment patients.
\end{abstract}

Materials and methods: Patients with differentiated thyroid cancer received $150 \mathrm{mCi} \mathrm{RAl}$ after total thyroidectomy. All patients were pretreated with $1 \mathrm{mg}$ granisetron and $4 \mathrm{mg}$ dexamethasone. Patients in the amifostine arm $(n=27)$ were prospectively enrolled and received $500 \mathrm{mg}$ amifostine subcutaneously. Adverse effects were scored based on the CTCAE at 1 month, 6 months, and yearly intervals using a physician administered questionnaire. The results were compared with a retrospective no amifostine cohort $(n=22)$ for whom data was collected with the identical questionnaire.

Results: The overall incidence of xerostomia, sialadenitis, taste dysfunction and nausea in the treatment group was $26,22,52$ and 26\% respectively. Only grades 1 and 2 adverse effects were observed. The mean duration (days) of xerostomia (control vs treatment) -37.3 vs 21.9 ( $F$ test, $p=0.016$ ), taste dysfunction-45.5 vs 23.5 ( $F$ test, $p=0.001$ ), sialadenitis16.8 vs 7.5 and nausea-18.7 vs 5.1 .

Conclusion: In patients treated once with high dose RAI, who develop xerostomia, sialoadenitis, taste dysfunction, and/or nausea, the duration of symptoms appears to be reduced by pretreatment with $500 \mathrm{mg}$ of subcutaneous amifostine without significant treatment related adverse effects.

Keywords: Thyroid cancer, Radioprotection, Amifostine, Radioactive iodine, Prospective.

How to cite this article: Sandhu A, loffe V, Karakla D, Wadsworth JT, Mendoza A, Rao N, Dignan K, Mason E, Goffman TE. Prospective Single-Arm Study of Radioprotection by Amifostine in High Dose Radioactive lodine Therapy for Thyroid Cancer. J Postgrad Med Edu Res 2012;46(2):90-94.

Source of support: Nil

Conflict of interest: None declared

\section{INTRODUCTION}

Over 25,000 cases of thyroid carcinoma were diagnosed in 2005 and about $75 \%$ were well-differentiated carcinomas. ${ }^{1}$ The age-adjusted incidence in women has increased 4.3\% per year from 1992 though 2001, the fastest rise among malignancies tracked by SEER (surveillance epidemiology and end results). ${ }^{2}$ Differentiated thyroid cancer affects women 2.5 times the rate in men and most commonly presents in the fourth and fifth decades of life.

In our institution, total thyroidectomy followed by high dose 131-I RAI (radioactive iodine) remnant ablation is the standard treatment for patients with differentiated thyroid cancer. $^{3-8}$ Accumulation of RAI in the salivary glands ${ }^{9-11}$ and the gastrointestinal tract ${ }^{12}$ results in a high incidence of xerostomia, sialoadenitis, taste dysfunction and nausea. Moreover, since over one-third of patients eventually require more than one RAI administration and the adverse effects increase with accumulated dose, the potential for developing long-term effects is a real danger. These adverse effects are known to cause difficulties with mastication, swallowing, speech, oral health and a reduction in quality of life. ${ }^{13,14}$

A European quantitative double-blind, placebocontrolled randomized trial has shown that the radioprotector, amifostine (Ethyol, MedImmune Oncology, Inc., Gaithersburg, MD), reduced parenchymal damage in salivary glands caused by high dose RAI. ${ }^{15}$ Additionally, a well-established literature documents the efficacy of amifostine for salivary gland protection in head and neck cancer irradiation. ${ }^{16-21}$

We conducted a prospective single arm study to determine the incidence of xerostomia, sialoadenitis, taste dysfunction and nausea as well as whether the radioprotector amifostine could decrease the duration of these adverse effects in patients treated with RAI one time.

\section{MATERIALS AND METHODS}

In our institution, patients with well-differentiated thyroid cancer receive $150 \mathrm{mCi}$ RAI after total thyroidectomy for eradication of the thyroid remnant and any remaining cancer. Additionally, patients undergo whole body RAI scanning to access for metastatic disease and proper biodistribution 48 hours and 7 days post-RAI administration.

This was a prospective, nonrandomized, open-label study. Eligibility included age $\geq 16$ years, initial systolic blood pressure $>80 \mathrm{~mm} \mathrm{Hg} \mathrm{(>100} \mathrm{mm} \mathrm{Hg} \mathrm{in} \mathrm{patients}$ $\geq 50$ years), patients scheduled to receive a RAI treatment following total thyroidectomy for localized or metastatic well-differentiated thyroid carcinoma and absence of contraindications to amifostine. The study was conducted after approval was granted by the internal review board. 
All patients were pretreated with 1mg granisetron and 4 mg dexamethasone 1 hour before receiving RAI to prevent RAI induced nausea. Patients in the amifostine arm $(\mathrm{n}=27)$ were prospectively enrolled and received $500 \mathrm{mg}$ amifostine subcutaneously ( $250 \mathrm{mg}$ in each lateral deltoid) 15 to 30 minutes before RAI treatment. Amifostine was provided to patients enrolled in the study by MedImmune Oncology, Inc. All patients were instructed to maintain salivary gland stimulation to decrease impairment of salivary gland function (hard candies), to utilize prune juice to keep the bowels active and to maintain a high fluid intake so as to reduce the local collection of radioisotope in the bowel or bladder. All patients were dosed in an outpatient setting in accordance with guidelines of the US Nuclear Regulatory Commission (www.nrc.gov). Adverse effects were scored based on the National Institutes of Health Common Terminology Criteria (v3.0) for adverse events at 1 month, 6 months and yearly intervals using a physician administered questionnaire. Acute events were defined as those present for $\leq 6$ months and chronic events for $>6$ months posttreatment. The results were compared with a retrospective no amifostine cohort $(\mathrm{n}=22)$ for whom data was collected with the identical questionnaire. The difference in means of symptom duration between groups was based on the t-test and the variance of side effect duration between the two groups was examined with the $\mathrm{F}$ test to the $95 \%$ confidence interval. The software package used for statistical analysis was GraphPad Prism 3.03, San Diego, CA.

\section{RESULTS}

Twenty-seven patients were prospectively enrolled in the amifostine treatment arm. These patients were compared to 22 historical controls. The two groups were well balanced with regard to baseline characteristics (Table 1). The duration of follow-up in the control and treatment arms was 27.9 and 6.4 months (mean) and 23.4 and 7.9 months (median) respectively. Only grades 1 and 2 RAI induced toxicities were observed. The incidence of grades 1 or 2 xerostomia, sialoadenitis, taste dysfunction and nausea in the control and treatment groups are presented in Table 2. The mean duration of RAI induced toxicities after high dose RAI administration for control and treatment groups is shown in Table 3.

The mean duration of xerostomia (control vs treatment) was 37.3 vs 21.9 days ( $F$ test, $\mathrm{p}=0.016$ ). The mean duration of taste dysfunction was $45.5 \mathrm{vs} 23.5$ days ( $\mathrm{F}$ test, $\mathrm{p}=0.001$ ). The mean duration of sialoadenitis was 16.8 vs 7.5 days. The mean duration of nausea was 18.7 vs 5.1 days. The variance in symptom duration was statistically decreased for xerostomia and taste dysfunction while a strong trend existed for sialoadenitis and nausea (Fig. 1). The only documented adverse effect to single dose amifostine was injection site rash (grade 1 only) which developed in 5/27 (18.5\%) and resolved spontaneously by 2 weeks.

\section{DISCUSSION}

The physical half-life of RAI is 8 days but the biological half-life is largely dependent on the presence of thyroid tissue. Since RAI is administered after thyroidectomy, the biological half-life of RAI is expected to be short, excreted in the kidneys within several hours. ${ }^{15}$ There are cases of heavy tumor burden in which the biologic half-life is longer.

Amifostine (WR-2721) is an organic thiophosphate prodrug that rapidly $(\mathrm{T} 1 / 2<1$ minute) distributes throughout the plasma compartment. There it is quickly dephosphorylated by alkaline phosphatase to the active free thiol

\begin{tabular}{lcc}
\multicolumn{3}{c}{ Table 1: Baseline characteristics } \\
\hline & \multicolumn{2}{c}{ Treatment group } \\
\cline { 2 - 3 } & $\begin{array}{c}\text { Control } \\
(n=22)\end{array}$ & $\begin{array}{c}\text { Amifostine } \\
(n=27)\end{array}$ \\
\hline & & \\
\hline Age, years & 50.5 & 44 \\
- Median & Range & $17-73$ \\
Sex, n (\%) & $31-76$ & \\
- Men & $6(27.3)$ & $6(22.2)$ \\
- Women & $16(72.7)$ & $21(77.8)$ \\
Histology, n (\%) & & \\
- Papillary & $14(63.8)$ & $18(66.7)$ \\
- Follicular & $1(4.5)$ & $4(14.8)$ \\
- Papillary & $7(31.8)$ & $5(18.5)$ \\
- Follicular variant & & \\
Disease stage, $n$ (\%) & & $17(63.0)$ \\
- 1 & $10(45.5)$ & $5(18.5)$ \\
- 2 3 & $9(40.9)$ & $3(11.1)$ \\
- 4 & $1(4.5)$ & $2(7.4)$ \\
\hline
\end{tabular}

$\begin{aligned} & \text { Table 2: Incidence of RAl induced toxicities in the control and } \\
& \text { treatment arms }\end{aligned}$
\begin{tabular}{ccc} 
Patients reporting, $n(\%)$ \\
\cline { 2 - 3 } & $\begin{array}{c}\text { Control } \\
(n=22)\end{array}$ & $\begin{array}{c}\text { Amifostine } \\
(n=27)\end{array}$ \\
\hline Xerostomia & $6(27)$ & $7(26)$ \\
Taste dysfunction & $8(36)$ & $14(52)$ \\
Sialoadenitis & $4(18)$ & $6(22)$ \\
Nausea & $6(27)$ & $7(26)$ \\
\hline
\end{tabular}

\begin{tabular}{lccc}
\multicolumn{4}{c}{ Table 3: Mean duration of RAl induced toxicities } \\
\hline & $\begin{array}{l}\text { Control } \\
\text { mean }( \pm S E M), d\end{array}$ & $\begin{array}{c}\text { Treatment } \\
\text { mean }( \pm S E M), d\end{array}$ & $\begin{array}{c}p \text {-value } \\
\text { (F test) }\end{array}$ \\
\hline Xerostomia & $37.3(13.2)$ & $21.9(4.6)$ & 0.016 \\
Taste dysfunction & $45.5(13.7)$ & $23.5(3.9)$ & 0.001 \\
Sialoadenitis & $16.8(7.8)$ & $7.5(4.1)$ & 0.178 \\
Nausea & $18.7(7.1)$ & $5.1(3.3)$ & 0.063 \\
\hline
\end{tabular}

SEM: Standard error of the mean; d: days 
(WR-1065) and is taken up into the tissues. ${ }^{22}$ In the first 30 minutes after amifostine administration, the drug uptake into normal tissues, such as the salivary glands is up to 100 fold greater than in tumor tissues. The half-life of amifostine in normal tissues is approximately 24 hours. ${ }^{23}$ Thus, amifostine is an ideal radioprotector in thyroid cancer because RAI damages normal tissues within the first several hours upon administration. Biodistribution studies have found that the highest concentration of amifostine and its metabolites are found in salivary glands ${ }^{24-27}$ but accumulation in thyroid tissue was negligible. ${ }^{15,28}$ WR-1065 exerts its cytoprotective effect by acting as a free-radical scavenger and prevents tissue damage from oxygen freeradicals produced by radiation. ${ }^{29}$ Amifostine does not confer protection to tumor cells because the active form (WR-1065) is selectively concentrated in normal tissues. ${ }^{23,29}$ Multiple clinical trials have suggested that amifostine does not protect tumor cells. ${ }^{16,30-35}$

Amifostine is approved by the FDA for administration intravenously. Recently, investigators have shown that subcutaneous administration has equivalent activity with improved tolerability. ${ }^{36-39}$

A double-blind, placebo-controlled randomized trial using quantitative salivary gland scintigraphy has shown that amifostine pretreatment reduces both acute and chronic xerostomia in patients treated with high dose RAI. ${ }^{15}$

The current study examined whether amifostine could reduce the duration of xerostomia, sialoadenitis, taste dysfunction, and/or nausea subsequent to a $150 \mathrm{mCi}$ therapeutic dose of RAI in the postoperative treatment of well-differentiated thyroid cancer. This report evaluates patients treated with RAI one time in order to identify baseline adverse effect incidence rates and to assess for the efficacy of amifostine without the confounding factors associated with multiple RAI doses.

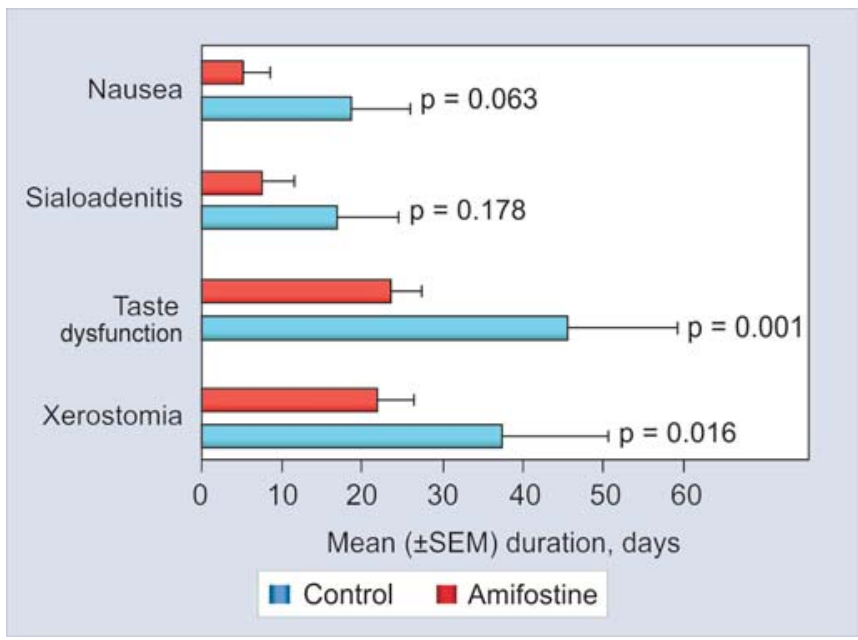

Fig. 1: Duration of toxicities after high dose RAI treatment
Salivary glands concentrate iodine 30 to 40 times the plasma level and have a dose dependent reduction in function following RAI. ${ }^{9,10}$ Xerostomia and sialoadenitis historically have been reported to occur in approximately $10 \%$ of patients who receive RAI therapy and most frequently in patients receiving multiple treatments. ${ }^{9,40,41}$ More recently, our group reported acute xerostomia in 21\% and acute sialoadenitis in $16 \%{ }^{42}$ Chronic xerostomia occurred in $35 \%$ of patients receiving multiple treatments of RAI with this figure reduced to $9 \%$ after amifostine subcutaneous pretreatment. ${ }^{42}$ The current study prospectively evaluated the incidence of xerostomia and sialoadenitis in the treatment arm and found the incidence of each is approximately $25 \%$ (Table 2). When compared to a retrospective historical control from our department, amifostine subcutaneous pretreatment resulted in a statistically significant reduction in duration of xerostomia and a trend for a reduction in sialoadenitis (Fig. 1).

Taste dysfunction historically has been reported in up to $48 \%$ of patients treated with 150 to $200 \mathrm{mCi}$ of RAI. ${ }^{43}$ Our prospective results indicate a comparable incidence rate of $52 \%$. The duration of taste dysfunction was significantly reduced with subcutaneous amifostine pretreatment (see Fig. 1).

Nausea has been reported in 50 to $67 \%$ of patients treated with high dose $\mathrm{RAI}^{40,44}$ due to accumulation of RAI in the gastrointestinal tract. ${ }^{12}$ The current study revealed a $26 \%$ incidence of nausea which was not different from the nonamifostine arm. This indicates that subcutaneous pretreatment with single dose amifostine does not result in amifostine induced nausea-a well known side effect in daily amifostine administration protocols. Interestingly, amifostine pretreatment resulted in a strong trend $(p=0.063)$ for the decrease in the duration of nausea (see Fig. 1). This supports the theory that amifostine protects the gastrointestinal tract from RAI induced nausea.

A recent review ${ }^{45}$ on the use of RAI supported the use of larger ablation doses which is known to be more effective in terms of complete ablation of remnant thyroid. The dose between 100 to $150 \mathrm{mCi}$ is standard practice for high-risk disease. Dose of mCi have been tried with disappointing results resulting and ablation is achieved only in $60 \%$ of cases. Complete ablation is well known to reduce relapse rates which can only be achieved with higher doses.

\section{CONCLUSION}

This single arm prospective study confirmed the high incidence rates of xerostomia (26\%), sialoadenitis (22\%), taste dysfunction (52\%) and nausea (26\%) after single high dose RAI administration for the postoperative treatment of well-differentiated thyroid cancer. There were no cases of 
chronic adverse effects from single dose RAI. We have shown that subcutaneous pretreatment with amifostine decreases the duration of these RAI induced side effects without significant treatment related adverse effects. Pretreatment with subcutaneous amifostine can be easily incorporated into a clinical practice and may decrease or prevent potentially debilitating symptoms in an otherwise young and healthy patient population. We however caution that the routine use of amifostine is not recommended based on this study. Larger prospective studies should answer this important question. We are analyzing data from patients treated with multiple doses of RAI to determine, whether amifostine can prevent chronic RAI-induced toxicities.

\section{DISCLOSURE}

This study was conducted in the Department of Radiation Oncology at Sentara Norfolk General Hospital, a department of the Eastern Virginia Medical School. MedImmune Oncology, Inc. had no rights to oversee or review the results of the study.

\section{ACKNOWLEDGMENT}

We would like to thank MedImmune Oncology, Inc. provided amifostine to study patients.

\section{REFERENCES}

1. Jemal A, Murray T, Ward E, et al. Cancer statistics. CA Cancer J Clin 2005;55:10-30.

2. Ries L, Eisner M, Kosary C, et al. SEER cancer statistics review 1975-2001. Bethesda: National Cancer Institute 2004.

3. Beierwaltes WH, Rabbani R, Dmuchowski C, et al. An analysis of ablation of thyroid remnants with I-131 in 511 patients from 1947-1984: Experience at University of Michigan. J Nucl Med 1984;25:1287-93.

4. Doi SA, Woodhouse NJ. Ablation of the thyroid remnant and 131I dose in differentiated thyroid cancer. Clin Endocrinol (Oxf) 2000;52:765-73.

5. Loh KC, Greenspan FS, Gee L, et al. Pathological tumor-nodemetastasis (pTNM) staging for papillary and follicular thyroid carcinomas: A retrospective analysis of 700 patients. J Clin Endocrinol Metab 1997;82:3553-62.

6. Rawson RW, Rall JE, Peacock W. Limitations and indications in the treatment of cancer of the thyroid with radioactive iodine. J Clin Endocrinol Metab 1951;11:1128-42.

7. Sweeney DC, Johnston GS. Radioiodine therapy for thyroid cancer. Endocrinol Metab Clin North Am 1995;24:803-39.

8. Wartofsky L. Papillary carcinoma. In: Wartofsky L. Thyroid cancer: A comprehensive guide to clinical management. Totowa: Humana Press Inc 2000.

9. Allweiss P, Braunstein GD, Katz A, et al. Sialadenitis following I-131 therapy for thyroid carcinoma: Concise communication. J Nucl Med 1984;25:755-58.

10. Spiegel W, Reiners C, Borner W. Sialoadenitis following I-131 therapy for thyroid carcinoma: Concise communication. J Nucl Med 1985;26:816.

11. Mandel SJ, Mandel L. Radioactive iodine and the salivary glands. Thyroid 2003;13:265-71.
12. Bohuslavizki KH, Klutmann S, Jenicke L, et al. Radioprotection of salivary glands by S-2-(3-aminopropylamino)-ethylphosphorothioic (amifostine) obtained in a rabbit animal model. Int J Radiat Oncol Biol Phys 1999;45:181-86.

13. Wasserman TH, Brizel DM, Henke M, et al. Influence of intravenous amifostine on xerostomia, tumor control, and survival after radiotherapy for head-and-neck cancer: 2-year follow-up of a prospective, randomized, phase III trial. Int J Radiat Oncol Biol Phys 2005;63:985-90.

14. Wasserman T, Mackowiak JI, Brizel DM, et al. Effect of amifostine on patient assessed clinical benefit in irradiated head and neck cancer. Int J Radiat Oncol Biol Phys 2000;48:1035-39.

15. Bohuslavizki KH, Klutmann S, Brenner W, et al. Salivary gland protection by amifostine in high-dose radioiodine treatment: Results of a double-blind placebo-controlled study. J Clin Oncol 1998;16:3542-49.

16. Brizel DM, Wasserman TH, Henke M, et al. Phase III randomized trial of amifostine as a radioprotector in head and neck cancer. J Clin Oncol 2000;18:3339-45.

17. McDonald S, Meyerowitz C, Smudzin T, et al. Preliminary results of a pilot study using WR-2721 before fractionated irradiation of the head and neck to reduce salivary gland dysfunction. Int J Radiat Oncol Biol Phys 1994;29:747-54.

18. Antonadou D, Pepelassi M, Synodinou M, et al. Prophylactic use of amifostine to prevent radiochemotherapy-induced mucositis and xerostomia in head-and-neck cancer. Int J Radiat Oncol Biol Phys 2002;52:739-47.

19. Buntzel J, Glatzel M, Kuttner K, et al. Amifostine in simultaneous radiochemotherapy of advanced head and neck cancer. Semin Radiat Oncol 2002;12:4-13.

20. Buntzel J, Kuttner K, Frohlich D, et al. Selective cytoprotection with amifostine in concurrent radiochemotherapy for head and neck cancer. Ann Oncol 1998;9:505-09.

21. Buntzel J, Schuth J, Kuttner K, et al. Radiochemotherapy with amifostine cytoprotection for head and neck cancer. Support Care Cancer 1998;6:155-60.

22. Spencer CM, Goa KL. Amifostine. A review of its pharmacodynamic and pharmacokinetic properties, and therapeutic potential as a radioprotector and cytotoxic chemoprotector. Drugs 1995;50:1001-31.

23. Yuhas JM. Active versus passive absorption kinetics as the basis for selective protection of normal tissues by S-2-(3-aminopropylamino)-ethylphosphorothioic acid. Cancer Res 1980;40: 1519-24.

24. Rasey JS, Krohn KA, Grunbaum Z, et al. Synthesis, biodistribution, and autoradiography of radiolabeled S-2-(3methylaminopropylamino) ethylphosphorothioic acid (WR3689). Radiat Res 1986;106:366-79.

25. Rasey JS, Spence AM, Badger CC, et al. Specific protection of different normal tissues. Pharmacol Ther 1988;39:33-43.

26. Utley JF, Phillips TL, Kane LJ. Protection of normal tissues by WR2721 during fractionated irradiation. Int J Radiat Oncol Biol Phys 1976;1:699-703.

27. Utley JF, Quinn CA, White FC, et al. Protection of normal tissue against late radiation injury by WR-2721. Radiat Res 1981;85: 408-15.

28. Washburn LC, Carlton JE, Hayes RL. Distribution of WR-2721 in normal and malignant tissues of mice and rats bearing solid tumors: Dependence on tumor type, drug dose and species. Radiat Res 1974;59:475-83.

29. Ethyol (amifostine). Full Prescribing Information MO, Inc, Gaithersburg, MD 2003. 
30. Betticher DC, Anderson H, Ranson M, et al. Carboplatin combined with amifostine, a bone marrow protectant, in the treatment of non-small-cell lung cancer: A randomised phase II study. Br J Cancer 1995;72:1551-55.

31. Glover D, Glick JH, Weiler C, et al. Phase I/II trials of WR2721 and cis-platinum. Int J Radiat Oncol Biol Phys 1986;12: 1509-12.

32. Kemp G, Rose P, Lurain J, et al. Amifostine pretreatment for protection against cyclophosphamide-induced and cisplatininduced toxicities: Results of a randomized control trial in patients with advanced ovarian cancer. J Clin Oncol 1996;14: 2101-12.

33. Komaki R, Lee JS, Milas L, et al. Effects of amifostine on acute toxicity from concurrent chemotherapy and radiotherapy for inoperable non-small-cell lung cancer: Report of a randomized comparative trial. Int J Radiat Oncol Biol Phys 2004;58: 1369-77.

34. Liu T, Liu Y, He S, et al. Use of radiation with or without WR2721 in advanced rectal cancer. Cancer 1992;69:2820-25.

35. Schiller JH, Storer B, Berlin J, et al. Amifostine, cisplatin, and vinblastine in metastatic non-small-cell lung cancer: A report of high response rates and prolonged survival. J Clin Oncol 1996;14:1913-21.

36. Koukourakis MI, Kyrias G, Kakolyris S, et al. Subcutaneous administration of amifostine during fractionated radiotherapy: A randomized phase II study. J Clin Oncol 2000;18:2226-33.

37. Bardet E, Martin L, Calais G, et al. Preliminary data of the GORTEC 2000-02 phase III trial comparing intravenous and subcutaneous administration of amifostine for head and neck tumors treated by external radiotherapy. Semin Oncol 2002;29: 57-60.

38. Anne PR, Curran WJ, Jr. A phase II trial of subcutaneous amifostine and radiation therapy in patients with head and neck cancer. Semin Radiat Oncol 2002;12:18-19.

39. Thorstad WL, Haughey B, Chao KS. Pilot study of subcutaneous amifostine in patients undergoing postoperative intensity modulated radiation therapy for head and neck cancer: Preliminary data. Semin Oncol 2003;30:96-100.

40. Van Nostrand D, Neutze J, Atkins F. Side effects of rational dose iodine-131 therapy for metastatic well-differentiated thyroid carcinoma. J Nucl Med 1986;27:1519-27.

41. Edmonds CJ, Smith T. The long-term hazards of the treatment of thyroid cancer with radioiodine. Br J Radiol 1986;59:45-51.

42. Mendoza A, Shaffer B, Karakla D, et al. Quality of life with well-differentiated thyroid cancer: Treatment toxicities and their reduction. Thyroid 2004;14:133-40.

43. Varma V, Dai W, Henkin R. Taste dysfunction in patients with thyroid cancer following treatment with 131I. J Nucl Med 1992; 33:996.

44. Kahn S, Waxman A, Ramanna L, et al. Transient radiation effects following high dose 131I therapy for differentiated thyroid cancer (DTC). J Nucl Med 1994;35:15P.
45. Clarke SEM. The radioiodine therapy in differentiated thyroid cancer: A nuclear medicine perspective. Clinical oncology 2010; 22:430-37.

\section{ABOUT THE AUTHORS}

\section{Ajay Sandhu}

Department of Radiation Oncology, University of California San Diego, CA, USA

\section{Vladimir loffe}

21st Century Oncology, Peninsula Cancer Care Center, Salisbury MD, USA

\section{Daniel Karakla}

Department of Otolaryngology, Eastern Virginia Medical School Head and Neck Surgery, Norfolk, VA, USA

\section{J Trad Wadsworth}

Department of Otolaryngology, Eastern Virginia Medical School Head and Neck Surgery, Norfolk, VA, USA

\section{April Mendoza}

Florida Radiation Oncology Group, Jacksonville, FL, USA

\section{Nikhil Rao}

Department of Radiation Oncology, University of Texas, Galveston TX, USA

\section{Kathleen Dignan}

Sentara Norfolk General Hospital, Norfolk, VA, USA

\section{Elizabeth Mason}

Department of Endocrinology, Eastern Virginia Medical School Norfolk, VA, USA

\section{Thomas E Goffman}

Department of Radiation Oncology, Eastern Virginia Medical School Norfolk, VA, USA

\section{CORRESPONDING AUTHOR}

Ajay Sandhu, Department of Radiation Oncology, 3960 Health Sciences Drive, La Jolla, CA 92093, USA, e-mail: apsandhu@ucsd.edu 